\title{
Coping with Fears of Covid-19 Pandemic Among Nursing Students During Clinical Practice: Malawi's Perspective
}

\author{
Masumbuko Albert Baluwa (iD \\ Alice Konyani \\ Mep Coretta Chipeta (ID) \\ Getrude Munthali \\ Lucky Mhango \\ Etta Chimbe \\ Florence Lungu \\ Ferestas Mpasa
}

Department of Nursing and Midwifery, Mzuzu University, Mzuzu, 2, Malawi
Correspondence: Masumbuko Albert Baluwa

Department of Nursing and Midwifery, Mzuzu University, Private Bag 20I,

Luwinga, Mzuzu, 2, Malawi

Tel +265 999229714

Email mbukobaluwa@yahoo.co.uk
Purpose: Fears of the Covid-19 pandemic have brought additional psychological pressure among nursing students. Nursing students at Mzuzu University in Malawi resumed clinical practice amidst the first wave of the pandemic and completed their rotation from September to December 2020. However, it was not known how they were coping with fears of the Covid-19 pandemic during clinical practice and this had set the impetus for conducting this study.

Methods: The study used qualitative approach employing a descriptive phenomenological design. Four focus group discussions (FGDs) were conducted on students who had completed a clinical rotation during the first wave of the Covid-19 pandemic.

Results: Four themes emerged from the data analysis, and these were staying positive amidst the Covid-19 pandemic; applying the Covid-19 preventive measures; the role of religion and use of avoidance strategies.

Conclusion: Students should be encouraged to use coping strategies that have been proven to promote psychological well-being in times of crisis such as the Covid-19 pandemic.

Keywords: Covid 19 pandemic, coping strategies, nursing students, clinical learning

\section{Introduction}

The highly contagious and fatal nature of the Covid-19 continues to place immense pressure on hospitals and psychological well-being of healthcare workers. ${ }^{1}$ This pandemic has also affected clinical education for nursing students whose programme is already known to be highly stressful ${ }^{2,3}$ even without additional challenges presented by Covid-19. The coronavirus disease has led to fears and increased stress levels among nursing students who strive to acquire the requisite skills and competencies necessary for patient care, ${ }^{4}$ hence requiring additional coping skills. Lazarus and Folkman ${ }^{5}$ describe coping strategies as constantly changing cognitive and behavioural efforts to manage specific external or internal demands that are far beyond the existing resources of the person. Coping plays a significant role in the process of stress adjustment and promotion of quality care in clinical practice, ${ }^{6}$ as such, it is essential to explore it in the context of the crisis caused by the Covid-19 pandemic.

Nursing students naturally face myriad challenges in the clinical learning environment which is more stressful than the theoretical aspect of the training. ${ }^{6}$ Furthermore, moderate-to-severe stress symptoms of anxiety and depression have been reported during pandemics, ${ }^{7}$ which has changed educational attitudes and strategies. $^{8}$ Health professional students may experience decreased psychomotor 
concentration, suffer learning disabilities and avoid learning activities which may negatively affect their academic achievements. ${ }^{9}$ A study conducted among nursing students during the SARS outbreak in Hong Kong showed that nursing students perceived themselves as being at higher risk of infection. ${ }^{10}$ Clinical experiences for students during the pandemics, such as these have been more demanding than usual, often been described as unsafe, overwhelming and psychologically stressful. ${ }^{4}$ Therefore, fear of catching the virus and dying of the pandemic is very high among nursing students, hence demanding additional coping skills.

Literature has also revealed different coping strategies that nursing students are using in the wake of Covid-19 pandemic. ${ }^{7,8}$ The latest research in China, for example, has shown that professional nurses used problem-focused coping methods more than college nursing students who chose immature or negative coping strategies. ${ }^{11}$ Moreover, staying optimistic has been reported as another active coping behaviour which involves a set of actions aimed at having a positive attitude in dealing with everything in life including during the Covid-19 pandemic. ${ }^{12,13}$ Similarly, religion has also been reported as helpful in promoting adaptation amidst the pandemic. Spiritual beliefs assist in attaching meaning to events which protect individuals against worsening the stressful experience, and adoption of health promotive behavior during the Covid-19 pandemic. ${ }^{7,8,10}$ Furthermore, some students use avoidance coping mechanisms, such as eating and spending time on the internet during pandemics. ${ }^{14}$ Although these represent coping strategies among nursing students elsewhere, paucity of literature for Malawi's nursing students necessitated this study. It is argued that exploration of nursing students' experiences of coping with clinical stressors increases students' awareness of their coping mechanisms. ${ }^{15}$ Therefore, there was a need to understand student's coping strategies in order to effectively meet their psychological needs during pandemics such as the Covid-19.

In Malawi, research studies have revealed several challenges that students have to cope with in clinical practice even before the emergence of the Covid-19 pandemic. ${ }^{2,16,17}$ For instance, inadequate personal protective equipment (PPE) for infection prevention and shortage of material and human resources for patient care have been reported as some of these challenges. ${ }^{16,17}$ Likewise, lack of PPE was also found to be associated with higher anxiety among practicing nursing students, unlike those that had easy access to such resources. ${ }^{10}$ Similarly, in a study from Saudi-Arabia, during the MERS outbreak, healthcare students expressed their reluctance to work in facilities with inadequate infection control isolation policies. ${ }^{18}$ In the face of these challenges, Malawi's nursing students have reportedly been using active coping and planning as coping strategies in overcoming known stressors associated with the nursing programme. ${ }^{2}$ However, it can be argued that the novel Covid-19 pandemic has brought unique challenges, and that it was necessary to understand how these students were coping with fears during their clinical practice.

Nursing schools all over the world as well as in developing countries like Malawi responded to the coronavirus pandemic following the guidelines of the World Health Organisation (WHO). On 20th March 2020, the COVID19 pandemic was declared a national disaster in Malawi by the head of state, and Mzuzu University officially closed on 23rd March 2020. Clinical practice was indefinitely suspended for Nursing and Midwifery students. On 14th September 2020, students were called back to resume their clinical placement, although the pandemic was still persistent on the ground. The Nursing Department conducted Covid-19 orientation to the students during which they were supplied with PPE preparing them for the resumption of clinical practice in their respective areas. Thus, these students completed clinical rotation in December 2020 just before the beginning of the second wave. Since these students resumed clinical practice amidst this pandemic, their fears and coping strategies were not known and understood. This study therefore aimed at exploring fears and coping strategies nursing students had during the period of clinical practice. Accordingly, this paper reports coping strategies that these students were using in managing fears of the Covid-19 pandemic.

\section{Materials and Methods Study Design}

The study used qualitative approach by employing a descriptive phenomenological design to explore the coping strategies that were used by Nursing and Midwifery students during clinical experiences that happened amidst the Covid-19 pandemic. The purpose of phenomenological research is to describe particular phenomena, or the appearance of things, as lived experience. ${ }^{19}$ Since clinical learning is a human experience, the employment of phenomenological inquiry is justified. It is believed that only those who live the experience can describe it, ${ }^{20}$ hence the 
need to understand coping mechanisms the nursing students employed during the Covid-19 pandemic.

Qualitative research, in the main, emphasises the dynamic, holistic and individual aspects of the human experience, and attempts at capturing those experiences in their entirety within the context of those experiencing them. ${ }^{21}$ In this research, a qualitative approach was found to be the most suitable research method to explore coping mechanisms from the perspective of the students in their own setting.

\section{Study Setting and Sample}

The study was conducted at Mzuzu University campus since students had already completed their clinical rotation by the time this research protocol was approved. Participants were drawn from generic and upgrading Mzuzu University's nursing students who were in the clinical area from 14th September to December 2020. The assumption was that these students had now gained the experience that would help provide rich data for understanding their coping strategies. A purposeful sampling technique was used to recruit the study participants who volunteered and consented to take part, but subject to the theory of data saturation. There were four focus groups with ten participants in each group. Each focus group discussion comprised students sampled from the different levels and different clinical wards, units or departments.

\section{Data Collection}

Data were collected utilising a focus group interview guide which was developed to help the researchers maintain consistency between interviews and bring to mind the main areas to be explored, in the process, increasing credibility of the findings. ${ }^{22}$ The interview guide contained open-ended questions on coping mechanisms used in dealing with fears of the Covid-19 pandemic during patient care. The Focus group discussions (FDGs) were used to gather data. Collection of data was conducted in a quiet and friendly room within the university premises. Field notes were used to verify issues that arose during data collection and the interview environment. There was an exclusive and mutual dialogue with the participants who had shared experiences of how they coped with the fears related to the pandemic as they provided nursing care. The main question was "How were you coping with fears of the Covid-19 pandemic as you provided nursing care to the patients?" Probes pondered on thoughts, feelings and perceptions of the strategies implemented. Data were collected by an independent person who is not part of the researchers to avoid bias. A welcoming and friendly environment was created in order to develop a mutual and cordial relationship which enabled participants to freely open up their mind and give rich information. ${ }^{23}$

\section{Ensuring Methodological Rigour}

Methodological rigour was achieved in the following way: firstly, in order to ensure credibility, a member checking was done whereby the researcher returned to the participants to validate the findings. Considering the relationship between the researchers and the participants, the data collector also validated the findings.

Secondly, dependability was achieved by maintaining consistency in the process of data collection specifically by using the same main questions in the interview guide in all the FGDs to maintain consistency of the data findings. Furthermore, conformability was achieved by including extracts from the participants' narratives. The direct quotes also served to enhance the credibility of findings. Finally, the researchers have already provided a robust description of the research methodology, and the research context in order to help those who would want to use these findings, in their studies, make an informed decision when applying and generalizing them.

\section{Data Analysis}

Data were analysed using content analysis. Content analysis is an approach to quantify qualitative information by systematically sorting, and comparing items of information in order to summarise the information. ${ }^{24}$ The first step was to transcribe verbatim the interviews that were done in all the FGDs. All the researchers were involved in the transcription to familiarise themselves with the data. The next step was to listen and listen to the interviews. The research team verified the transcription by re-reading the transcribed data while listening and re-listening to the recorded data, in order to obtain a general sense about the whole context. This step was followed by identifying significant statements that pertained to the phenomena under study. The other step was to formulate meanings from these significant statements which were then sorted into themes, subthemes and subcategories. The findings were then integrated into an exhaustive description of the coping strategies utilised by the nursing students. Finally, validation of the findings was done by returning to the participants and data collector to compare the researchers' descriptive results with their experience and data collected, respectively. 


\section{Ethical Considerations}

This study was conducted in accordance with the Declaration of Helsinki. The study was approved by the Mzuzu University Research Ethics Committee (approval number MZUNIREC/DOR/20/06). Participants provided a written informed consent to take part in the study. Furthermore, consent was sought on the possibility of publishing their anonymised responses to which they all agreed. The researchers recruited a nurse educator from another nursing college to collect data to prevent undue influences from familiar nurse educators. The researchers also respected the participants' rights to privacy, confidentiality, anonymity and autonomy as the pillars of justice and fair treatment of subjects.

\section{Results}

\section{Demographic Data}

A total of 40 student nurses were recruited in the study of which, 18 were males and 22 were females. Their level of study and area of clinical experience have been well detailed in Table 1.

\section{Emerged Themes}

Four themes emerged from the data: thus, staying positive amidst the Covid-19 pandemic; applying the Covid-19 preventive measures; the role of religion, and use of avoidance strategies.

\section{Theme I: Staying Positive Amidst the Covid-19}

\section{Pandemic}

Under this theme, three (3) subthemes emerged, which were hope of surviving after being infected by the virus; reduced number of Covid-19 deaths, and trusting own body defenses.

\section{Hope of Surviving After Being Infected}

Participants were optimistic that if they get infected while providing care, they will be able to recover like most people in the community who tested positive for the virus. One participant gave this narrative:

"I could see that some patients were getting better, I could hear that such and such a patient who had Covid has now recovered". (Participant 12)

In addition, they were encouraged by the healthcare workers that got infected recovered, and were on the ground again providing care. One of the participants narrated:

"The other thing that we were doing with the Covid - 19 was to see how other nurses were surviving on the same situations. So if they were surviving, I said, I am also going to survive". (Participant 15)

Another participant also had this to say:

"I saw a number of healthcare workers who recovered, and still they resumed work, so that encouraged me to say they really wanted to help". (Participant 3 )

\section{Reduced Number of Covid-19 Deaths}

Participants also felt encouraged when they heard and saw that the number of deaths due to the Covid-19 was decreasing. This decline had then given them hope to still carry on caring for patients. One of the participants stated:

Table I Socio-Demographic Characteristics of the Respondents

\begin{tabular}{|l|l|l|l|l|}
\hline $\begin{array}{l}\text { FGD } \\
\text { NO }\end{array}$ & Program & $\begin{array}{l}\text { Level of } \\
\text { Study }\end{array}$ & $\begin{array}{l}\text { Number of } \\
\text { Participants }\end{array}$ & Clinical Placement Areas \\
\hline I & $\begin{array}{l}\text { Bsc Nursing and Midwifery (upgrading cohort I, } \\
2018 \text { intake) }\end{array}$ & 2 & 10 & $\begin{array}{l}\text { STI, ART clinics, and medical and } \\
\text { surgical wards }\end{array}$ \\
\hline 2 & $\begin{array}{l}\text { Bsc Nursing and Midwifery (upgrading cohort 2, } \\
2018 \text { intake) }\end{array}$ & 1 & 12 & Medical and surgical nursing wards \\
\hline 3 & $\begin{array}{l}\text { Bsc Nursing and Midwifery (upgrading cohort 3, } \\
2019 \text { intake }\end{array}$ & 1 & 8 & Family planning clinics \\
\hline 4 & $\begin{array}{l}\text { Bachelor of science nursing and midwifery 2018 } \\
\text { intake (generic) }\end{array}$ & 2 & 10 & $\begin{array}{l}\text { ART, STI clinics, medical and surgical } \\
\text { wards, }\end{array}$ \\
\hline & Total participants & & 40 & \\
\hline
\end{tabular}


"I could see few deaths per day or week, so this really encouraged me day in day out". (Participant 16)

\section{Trusting Own Body Defenses}

Students had a belief that they were still young, and that their bodies had the capacity to fight the coronavirus and recover well if they became infected during clinical practice. One of them narrated:

". So looking at the figures as well as who is at greater risk of developing into severe cases. So I was like, I think I can survive". (Participant 23)

Furthermore, after hearing and observing that there were less Covid-19 related deaths in Africa than in the western countries, participants had confidence that being black offered them additional protection. The excerpt illustrates:

"I was actively following what was happening in other countries. The whites seemed to have been more affected than the blacks were, hence I had confidence in my immunity, and so I coped". (Participant 15)

\section{Theme 2: Applying Covid-19 Preventive Measures in Clinical Practice}

Participants were strictly adhering to the infection prevention measures that they learnt in order to prevent themselves from contracting the virus. One participant had this to say:

"I tried my best that I could do everything possible so that I did not contract the virus. Like I had to make sure that I was wearing a mask, washing my hands and so on ...". (Participant 35)

Similarly, students were also actively looking for up-todate information on how to protect themselves from catching the virus. The following excerpt illustrates this:

"I also used to check updated information that helped. For example, on the internet there were some forums that used to write new information on how one may prevent themselves from catching the virus and everything about it". (Participant 2)

In addition, availability of lecturers in clinical area provided students with the much needed support and confidence to follow infection prevention measures. One participant narrated:

"when we saw our lecturers coming around to our various allocations, I could just tell myself that I should not stop providing care to patients who are in need of my help as long as I am following all the infection prevention measures". (Participant 35)

Besides this, students were prescreening clients for cardinal Covid-19 signs to ascertain if they were caring for a potentially positive client. One participant explained:

"I could sometimes perform screening of my patients. I could ask patients; are you coughing? Are you having any painful throat? Or whatever, so that I could be careful in case I was dealing with a possible Covid patient" (Participant 11)

\section{Theme 3: The Use of Religion}

Religion was also mentioned as one of the coping strategy to fears in relation to contracting the Covid-19 virus in clinical practice. One participant said:

"I left everything in the hands of God because he is the one who saves. So I coped”. (Participant 26)

Another participant corroborated and narrated:

"As for me, I just left everything in the hands of God, if I catch it I catch it, if I live, I live". (Participant 31)

Furthermore, another participant believed that it was a calling from God to join the nursing profession, and was therefore duty-bound to serve humanity. She had this to say:

"Joining nursing as a profession is a calling, and every one of us was handpicked by God to provide these services". (Participant 11)

\section{Theme 4: Using Avoidance Coping Strategies}

The narratives indicated that students also used avoidance strategies due to fear of contracting the coronavirus while in clinical practice. Although the students were in the clinical area to provide care, they were limiting themselves from being in close contacts with the clients to protect themselves from contracting the virus. A participant narrated;

"I was just observing physical distancing as I cared for my patients'. (Participant 10)

On the other hand, some participants admitted that observing social distance, while caring for clients, was compromising the quality of care they provided. See the extract below:

"I was giving the care but the care was not sufficient". (Participant 5) 
Another strategy was that participants were diverting their attention from thinking about the pandemic, and they were slowly forgetting about it as time passed by. One participant narrated:

"The fear just disappeared with time, and after caring for my patient, I just got used that maybe it's a way of life and the fears were just gone". (Participant 24)

\section{Discussion}

The study findings support the existing literature that students are adopting behaviours that promote their well-being while hoping for restoration of the traditional learning approach they used to have prior to the Covid-19 pandemic. ${ }^{25}$ This study found out that remaining positive was used as a coping strategy to the fear of catching the Covid-19 pandemic during clinical practice. Student's positivity came from the fact that, although the Covid-19 cases were being reported from the general public and healthcare workers alike, majority of these people were recovering. This positivity was further strengthened by the fact that they were still young and capable of overcoming the disease once infected. Similar finding of positive attitude towards the pandemic and the possibility of overcoming it was previously reported among Saudi nursing students. ${ }^{12}$ A positive attitude may influence students to adopt the same attitude in using preventive measures, which has been found to influence students' use of positive coping and reduce psychological distress. ${ }^{13}$ Therefore, positive attitude is likely to promote learning in clinical practice in the middle of the pandemic and facilitate adherence to preventive measures.

On the other hand, the study further revealed a positive attitude which bordered on a myth that being black offered additional protection from developing severe Covid-19 symptoms. This assumption still stands as an elevated myth since research evidence has not reached any consensus on which racial groups are more likely to develop severe Covid-19 symptoms. Moreover, some studies have reported substantially high mortality rates among black African Americans, ${ }^{26}$ while others crudely reported that race was not an independent predictor of developing severe Covid symptoms. ${ }^{27}$ This attitude offers a false sense of protection that may influence learners not to follow standard infection prevention measures while practicing in high-risk areas.

More importantly, the study also found out that most students were using infection prevention measures to protect themselves from acquiring the coronavirus during clinical practice. These included hand washing, putting on a mask and actively looking for up-to-date information on how to protect themselves from catching the virus. In support of this finding, most students apply protective measures because they are afraid of acquiring the infection, and are worried about the well-being of their family. ${ }^{28}$ Similarly, seeking information was previously reported as an active coping strategy against fears of the Covid-19. ${ }^{10}$ Being a novel disease, it is necessary that students get information about the virus so that they are adequately knowledgeable about prevention strategies. However, there is need to be cautious on searching and analysing new information on prevention of the Covid-19 virus as this has negative facets. For example, Huang et $\mathrm{al}^{11}$ found out that high awareness of the contagious and lethal nature of this new virus may result in more fear and stress. To this end, Kochuvaliayil et $\mathrm{al}^{29}$ reported that limiting time watching, reading or listening to news on social media were helpful coping strategies among Australian students during this pandemic. Therefore, there is need to ascertain if the information search was not due to more anxiety and panic as this could expose students to false and misleading information.

Availability of lecturers in clinical practice areas also provided students with support and encouragement. This allowed them to follow infection prevention measures and continue providing the needed nursing care. In support of this finding, students have in previous studies praised teacher support and faculty as a valuable resource in crisis. $^{28}$ Teachers may provide a trusted person whom students can talk to which has been a medium for them to share their concerns and feelings as a source of coping. ${ }^{29}$ To this end, faculty should make initiatives that support and promote self-efficacy to achieve the wellbeing of the students ${ }^{30}$ by assisting them cope with stress especially during pandemics such as the Covid-19.

In addition to this, students were also taking their own precautionary measures when managing clients with unknown Covid-19 status. Before the provision of care, some students were screening clients for cardinal Covid19 signs and symptoms to ascertain if they were caring for a potentially positive client. Although this is a problemsolving strategy, it could be an indicator of potential source of stigmatisation as well as increased anxiety on the students. In support of this, Huang et $\mathrm{al}^{11}$ established that the more measures taken to deal with the pandemic, the more they may lead to increased anxiety among the nursing students. This could be true considering that the Covid-19 may present in a person similar signs and 
symptoms to those of other conditions. Much as prescreening may assist in identifying potential patients, it could also create extreme dilemmas and anxieties as the students are caring for clients with conditions sharing similar presentations to those of the coronavirus disease.

The study also revealed that religion was one of the strategies used to cope with fears of contracting the Covid19 in clinical practice. Participants believed that God is the protector and could save them from contracting the virus in the line of duty. Use of spiritual support was also reported by Muslims and African traditional religious groups as a protective measure to fears of the Covid-19 pandemic. ${ }^{10}$ Further, studies have reported on the benefits of high spiritual support in lowering the risk of depression, ${ }^{7}$ and that individuals who often do religious meditation experience low stress levels. ${ }^{8}$ This finding is not strange in Malawi's context where $99 \%$ of its populations are believers of God. Religion is likely to promote adaptation among nursing students to still serve and learn amidst the pandemic.

The narratives further show that students were using avoidance coping strategies in overcoming anxiety related to contracting the coronavirus during clinical practice. Although the students were in the clinical area to practice care provision, they were limiting themselves from being in close contact with the patients. Keeping social distance is a public health intervention in reducing the spread of the coronavirus as stipulated by the WHO. The dilemma though is that nurses, according to their professional demands, are required to be close to their clients in clinical practice when providing care. Therefore, maintaining social distance with patients could be misconstrued and hence an ineffective coping method. Ineffective coping strategies have previously been reported to be associated with stressful events during the pandemic. ${ }^{14}$ The use of ineffective coping strategies indicates more fear and anxiety of the pandemic among the nursing students.

\section{Conclusions and Recommendations}

This study explored coping strategies that students were using while practicing amidst the Covid-19 pandemic. The study uncovered the use of both effective and ineffective coping strategies. Staying positive, use of infection prevention measures, and religion were identified as effective coping strategies. In agreement with Kim et al, ${ }^{7}$ students should be encouraged to use these coping mechanisms to help them maintain their psychological well-being. The researchers argue that active search for information and prescreening of clients by the students before provision of care may denote the experience of high anxiety associated with the pandemic. Limiting close contact with clients and diverting thinking about the pandemic were considered ineffective coping strategies in this study. To this end, academic authorities should work with the students to reduce the use of ineffective coping strategies. We support Rafati et $\mathrm{al}^{15}$ on the need for provision of regular training on effective coping strategies for students especially during pandemics such as the Covid-19. Further, teachers and clinical staff need to frequently update students on available scientific evidence on care and support for the Covid19 pandemic. This will thus separate facts from myths which may exacerbate fears, and use of ineffective coping strategies among students.

\section{Limitations}

This study was conducted at one public university in Malawi, which trains Registered nurse midwives, hence the findings presented here are only for students from this college. In addition, the study was qualitative and does not represent the most commonly used or the least effective or ineffective coping strategies that students use during this pandemic. Therefore, there is need for larger scale studies to explore coping strategies in Malawi's context so that effective student learning would continue even during pandemics.

\section{Acknowledgments}

The authors would like to acknowledge the contribution of Miss Eunice Nyirenda, a lecturer at St John's Institute of Health Sciences College of Nursing for conducting the four (4) FGDs during data collection for the study.

\section{Disclosure}

This study did not receive any support or sponsorship from any institution. The authors report no conflicts of interest in this work.

\section{References}

1. Lai J, Ma S, Wang Y, et al. Factors associated with mental health outcomes among health care workers exposed to coronavirus disease 2019. JAMA Netw Open. 2020;3(3):e203976-e203976. doi:10.1001/ jamanetworkopen.2020.3976

2. Baluwa MA, Lazaro M, Mhango L, Msiska G. Stress and coping strategies among Malawian undergraduate nursing students. Adv Med Educ Pract. 2021;12:547-556. doi:10.2147/AMEP.S300457

3. Labrague LJ, McEnroe-Petitte DM, Papathanasiou IV, et al. A cross-country comparative study on stress and quality of life in nursing students. Perspect Psychiatr Care. 2018;54(4):469-476. doi:10.1111/ ppc. 12248 
4. Agu CF, Stewart J, McFarlane-Stewart N, Rae T. Covid-19 pandemic effects on nursing education: looking through the lens of a developing country. Int Nurs Rev. 2021;68:153-158. doi:10.1111/ inr. 12663

5. Lazarus RS, Folkman S. Stress, Appraisal, and Coping. Springer publishing company; 1984.

6. Al-Gamal E, Alhosain A, Alsunaye K. Stress and coping strategies among Saudi nursing students during clinical education. Perspect Psychiatr Care. 2018;54(2):198-205. doi:10.1111/ppc.12223

7. Kim SC, Sloan C, Montejano A, Quiban C. Impacts of coping mechanisms on nursing students' mental health during Covid-19 lockdown: a cross-sectional survey. Nurs Rep. 2021;11(1):36-44. doi:10.3390/nursrep11010004

8. Abdulghani HM, Sattar K, Ahmad T, Akram A. Association of Covid19 pandemic with undergraduate medical students' perceived stress and coping. Psychol Res Behav Manag. 2020;13:871. doi:10.2147/PRBM.S276938

9. Al-Rabiaah A, Temsah M-H, Al-Eyadhy AA, et al. Middle East Respiratory Syndrome-Corona Virus (MERS-CoV) associated stress among medical students at a university teaching hospital in Saudi Arabia. J Infect Public Health. 2020;13(5):687-691. doi:10.1016/j. jiph.2020.01.005

10. Savitsky B, Findling Y, Ereli A, Hendel T. Anxiety and coping strategies among nursing students during the covid-19 pandemic. Nurse Educ Pract. 2020;46:102809. doi:10.1016/j.nepr.2020.102809

11. Huang L, Lei W, Xu F, Liu H, Yu L, Li Z. Emotional responses and coping strategies in nurses and nursing students during Covid-19 outbreak: a comparative study. PLoS One. 2020;15(8):e0237303. doi:10.1371/journal.pone.0237303

12. Begum F. Knowledge, attitudes, and practices towards COVID-19 among B. Sc. Nursing students in selected nursing institution in Saudi Arabia during COVID-19 outbreak: an online survey. Saudi J Nurs Health Care. 2020;3(7):194-198. doi:10.36348/sjnhc.2020. v03i07.002

13. Moore KA, Lucas JJ. COVID-19 distress and worries: the role of attitudes, social support, and positive coping during social isolation. Psychol Psychother Theory Res Pract. 2021;94(2):365-370. doi:10.1111/papt.12308

14. Temiz Z. Nursing students' anxiety levels and coping strategies during the COVID-19 pandemic. Int Arch Nurs Health Care. 2020;6:150.

15. Rafati F, Nouhi E, Sabzevari S, Dehghan-Nayeri N. Coping strategies of nursing students for dealing with stress in clinical setting: a qualitative study. Electron Physician. 2017;9(12):6120. doi:10.19082/6120

16. Kamphinda S, Chilemba EB. Clinical supervision and support: perspectives of undergraduate nursing students on their clinical learning environment in Malawi. Curationis. 2019;42(1):1-10. doi:10.4102/ curationis.v42i1.1812
17. Mbakaya BC, Kalembo FW, Zgambo M, et al. Nursing and midwifery students' experiences and perception of their clinical learning environment in Malawi: a mixed-method study. BMC Nurs. 2020;19(1):1-14. doi:10.1186/s12912-020-00480-4

18. Elrggal ME, Karami NA, Rafea B, et al. Evaluation of preparedness of healthcare student volunteers against Middle East respiratory syndrome coronavirus (MERS-CoV) in Makkah, Saudi Arabia: a cross-sectional study. $J$ Public Health. 2018;26(6):607-612. doi:10.1007/s10389-018-0917-5

19. Speziale HS, Streubert HJ, Carpenter DR. Qualitative Research in Nursing: Advancing the Humanistic Imperative. Lippincott Williams \& Wilkins; 2011.

20. Mapp T. Understanding phenomenology: the lived experience. $\mathrm{Br}$ $J$ Midwifery. 2013;16(5):308-311. doi:10.12968/bjom.2008.16.5. 29192

21. Polit DF, Beck CT. Nursing Research: Generating and Assessing Evidence for Nursing Practice. Lippincott Williams \& Wilkins; 2014.

22. Boyce C, Neale P. Conducting in-depth interviews: a guide for designing and conducting in-depth interviews for evaluation input. 2006.

23. Karnieli-Miller O, Strier R, Pessach L. Power relations in qualitative research. Qual Health Res. 2009;19(2):279-289. doi:10.1177/ 1049732308329306

24. Grove SK, Burns N, Gray J. The Practice of Nursing Research: Appraisal, Synthesis, and Generation of Evidence. Elsevier Health Sciences; 2012.

25. Majrashi A, Khalil A, Nagshabandi EA, Majrashi A. Stressors and coping strategies among nursing students during the COVID-19 pandemic: scoping review. Nurs Rep. 2021;11(2):444 459. doi:10.3390/ nursrep11020042

26. Hooper MW, Nápoles AM, Pérez-Stable EJ. Covid-19 and racial/ ethnic disparities. JAMA. 2020;323(24):2466-2467. doi:10.1001/ jama.2020.8598

27. Bhargava A, Fukushima EA, Levine M, et al. Predictors for severe COVID-19 infection. Clin Infect Dis. 2020;71(8):1962-1968. doi:10.1093/cid/ciaa674

28. Lovrić R, Farčić N, Mikšić Š, Včev A. Studying during the COVID19 pandemic: a qualitative inductive content analysis of nursing students' perceptions and experiences. Educ Sci. 2020;10(7):188. doi:10.3390/educsci10070188

29. Kochuvilayil T, Fernandez RS, Moxham LJ, et al. COVID-19: knowledge, anxiety, academic concerns and preventative behaviours among Australian and Indian undergraduate nursing students: a cross sectional study. J Clin Nurs. 2021;30:1-10.

30. Gibbons C, Dempster M, Moutray M. Stress, coping and satisfaction in nursing students. $J$ Adv Nurs. 2011;67(3):621-632. doi:10.1111/ j.1365-2648.2010.05495.x
Advances in Medical Education and Practice

\section{Publish your work in this journal}

Advances in Medical Education and Practice is an international, peerreviewed, open access journal that aims to present and publish research on Medical Education covering medical, dental, nursing and allied health care professional education. The journal covers undergraduate education, postgraduate training and continuing medical education including emerging trends and innovative models linking education, research, and health care services. The manuscript management system is completely online and includes a very quick and fair peer-review system. Visit http://www.dovepress.com/testimonials.php to read real quotes from published authors. 